\title{
Self-reported cold sensitivity in patients with traumatic hand injuries or hand-arm vibration syndrome - an eight year follow up
}

Ingela K Carlsson ${ }^{1,2^{*}}$ and Lars B Dahlin ${ }^{1,2}$

\begin{abstract}
Background: Cold sensitivity is a common complaint following hand injuries. Our aim was to investigate long-term self-reported cold sensitivity, and its predictors and the importance of sense of coherence (SOC), 8 years after a hand injury as well as in patients treated for Hand Arm Vibration Syndrome (HAVS) during the same time period.

Methods: Responses to the Cold Intolerance Symptom Severity (CISS) questionnaire and the Sense of Coherence (SOC) questionnaire were investigated in hand injured patients $(n=64)$ and in patients with HAVS $(n=26)$. The Mann-Whitney U-Test was used to identify significant differences between subgroups. When analysing predictors for cold sensitivity severity, the Spearman rank correlation ( $r_{S}$ coefficient) were used for quantitative predictive variables, Mann-Whitney U-Test for dichotomous variables and Kruskal-Wallis Test for multiple categorical data. The Wilcoxon's signed rank test was used to investigate longitudinal changes in outcome.

Results: There was a significant change in total CISS score for patients with traumatic hand injury, indicating fewer problems with cold sensitivity over time. Symptoms, such as stiffness, weakness and skin colour change on cold exposure, caused fewer problems, but perceived pain/aching and numbness remained unchanged as well as time needed for relief of symptoms on return to a warm environment. The negative impact of cold sensitivity on daily activities and at work was reduced, but problems when engaged in hobbies or when being exposed to cold wintry weather remained unchanged. None of the investigated predictors related to the hand injury were significantly associated with a change in cold sensitivity at the 8-year follow up. In contrast, no significant change in cold sensitivity was noted in the patients with HAVS for any of the situations included in the CISS questionnaire. A lower sense of coherence score correlated significantly with worse cold sensitivity (CISS score) in both patient groups.
\end{abstract}

Conclusions: The negative impact of cold sensitivity on daily life was reduced for patients with traumatic hand injury, but did not change over time in patients with HAVS. A low SOC is associated with worse cold sensitivity in such groups of patients. Information about relieving strategies should be provided for patients with cold sensitivity.

Keywords: Cold intolerance, Cold sensitivity, Cold Intolerance Symptom Severity questionnaire, HAVS, SOC, Traumatic hand injury

\footnotetext{
* Correspondence: ingela.k.carlsson@hotmail.com

'Department of Hand Surgery, Skane University Hospital, Lund University, Malmö SE-205 02, Sweden

${ }^{2}$ Department of Clinical Sciences Malmö - Hand Surgery, Lund University, Lund, Sweden
} 


\section{Background}

Cold sensitivity, described as "an exaggerated or abnormal reaction to cold exposure of the injured part, causing discomfort or the avoidance of cold", is a common complaint following a variety of hand injuries and diseases [1-10]. The onset of cold-induced symptoms or discomfort is generally reported to occur within the first few months following the injury [11,12]. Contradictory reports exist on whether or not a reduction in discomfort is seen over time and which factor that is linked most strongly to severity and relief of discomfort [8,12-15]. Furthermore, such information has not been presented from different patient populations, such as traumatic injuries and neuropathies. One factor that has to be considered in a long-term follow up is that the reduction of cold-induced symptoms, and the impact cold sensitivity may have on daily life, may result from changes in behaviour, e.g. occupational performance and pattern or access to other coping strategies $[16,17]$. How patients view their life and see the world as comprehensible, manageable and meaningful (sense of coherence - SOC) may also facilitate the adaptation process [18-20].

The pathophysiology behind the complex phenomenon of cold sensitivity remains unclear, thus, a multifactor aetiology, including bony, vascular and neural components, is suggested, which was previously confirmed by a high correlation between a Hand Injury Severity Score (HISS), indicating more severely injured hands, and worse self-reported cold sensitivity (CISS score) [21].

When defining symptoms and signs and clarifying the impact of cold sensitivity on daily life, it is important to use valid and reliable questionnaires, such as the Cold Intolerance Symptom Severity (CISS) questionnaire [14,22]. A cut-off value for abnormal self-reported cold sensitivity in a normal Swedish population has been established previously. It suggests that a total CISS score above 50 indicates abnormality [21]. Our aim was to investigate long-term, i.e. self-reported cold sensitivity 8 years after the occurrence of the hand injury as well as in patients treated for Hand Arm Vibration Syndrome (HAVS) during the same time period. Furthermore, we also looked for any predictors associated with some change in cold sensitivity over time for patients with traumatic hand injury, as well as the association between patients' sense of coherence and cold sensitivity.

\section{Method}

\section{Study groups and methods}

During the cold season of 2011 the Swedish version of the Cold Intolerance Symptom Severity (CISS) questionnaire and the 13-item condensed Sense of Coherence (SOC) questionnaire $[18,22]$ was sent to all patients $(n=118)$ with a registered diagnosis (patient register at University Hospital Malmö) of a digital or midcarpal amputation $(\mathrm{n}=52)$, a traumatic nerve lesion $(\mathrm{n}=36)$ or HAVS $(n=30)$, excluding those below 18 years of age. The patients with traumatic hand injury were treated during January-November 2003 and the patients with HAVS during 2002-2003 and responded to the Cold Intolerance Symptom Severity (CISS) questionnaire in 2004. The patients with a traumatic injury were surgically treated at the department following the decision of the individual treating surgeon. The severity of the hand injury for each patient was defined by the hand injury severity score (HISS) [23]. Since there were no significant differences in cold sensitivity (CISS 4-100) between patients with amputation injuries and those with nerve injuries either at 1 year or at 8 years follow up, these patients were subsumed in a single group (traumatic hand injuries). The diagnosis of HAVS was based on a history of vibration-induced symptoms, for example white fingers, and/or sensorineural symptoms, with or without impaired vibrotactile sense and neurophysiological findings, supporting the presence of HAVS, but excluding other causes of neuropathy. All patients and subjects were from the southern part of Sweden which has a mean temperature of $0^{\circ} \mathrm{C}$ during the cold season (www.smhi.se). One written reminder was sent out to the patients. Nine patients with a traumatic hand injury and one patient with HAVS had passed away since the initial survey in 2004 leaving a total of 108 patients. Ninety patients $(83 \%)$ (amputation $\mathrm{n}=37$, nerve-injury $\mathrm{n}=27$, HAVS $\mathrm{n}=26$ ) responded. No discernable differences were found between the responders and non-responders with respect to age and gender. There was an internal dropout for the CISS questionnaire (traumatic hand injury, $\mathrm{n}=4$, HAVS, $\mathrm{n}=2$ ) in that not all patients answered all questions included in the total CISS score at both one and 8 years follow up, leaving at total of 60 patients with traumatic hand injury and 24 patients with HAVS.

All participants gave their informed consent to participating in the study, which was approved by the Ethics Committee, Faculty of Medicine, Lund University.

\section{Data analyses}

Results are presented as median (range). The MannWhitney U-Test was used to identify significant differences between subgroups. When analysing predictors for cold sensitivity severity (CISS score) the Spearman rank correlation $\left(r_{S}\right)$ coefficient were used for quantitative predictive variables, the Mann-Whitney $U$-Test for dichotomous variables and the Kruskal-Wallis Test for multiple categorical data. The Wilcoxon's signed rank test to investigate the longitudinal changes in outcome. P-values of less than 0.05 were considered significant. Data were analysed using the SPSS software package, version 12.0.1. 


\section{Results}

The characteristics of the subjects and patients are described in Table 1. The patients with traumatic hand

Table 1 Characteristics of patients with traumatic hand injury and HAVS

\begin{tabular}{|c|c|c|}
\hline Parameter & $\begin{array}{l}\text { Traumatic hand } \\
\text { injury } n=64\end{array}$ & $\begin{array}{l}\text { HAVS } \\
n=26\end{array}$ \\
\hline Gender (male/female) & $50 / 14$ & $24 / 2$ \\
\hline Age at 8 year follow up 1,2 & $51(28-86)$ & $61(31-73)$ \\
\hline Smoker (yes/no) & $14 / 50$ & $4 / 22$ \\
\hline $\begin{array}{l}\text { Time since injury (years) at } \\
8 \text { year follow up }\end{array}$ & $8.25(7.75-9)$ & - \\
\hline $\begin{array}{l}\text { Years of vibration exposure at } \\
1 \text { year follow up }{ }^{1}\end{array}$ & - & $30(4-46)$ \\
\hline CISS score (abnormal/normal) ${ }^{4}$ & $17 / 43$ & $16 / 8$ \\
\hline $\begin{array}{l}\text { DASH score at } 1 \text { year follow up } \\
(0-100)^{5,1,6}\end{array}$ & $23(2-60)^{5}$ & $34(5-70)^{5}$ \\
\hline $\begin{array}{l}\text { Sense of coherence (SOC, range 13-91) } \\
\text { score at } 8 \text { year follow up } p^{3,7}\end{array}$ & $74(28-91)$ & $67(50-91)$ \\
\hline HISS at injury ${ }^{1,8}$ & $77(10-305)$ & - \\
\hline Vibration-induced white fingers $(\mathrm{VWF})^{9}$ & - & $15 / 26$ \\
\hline \multicolumn{3}{|l|}{ Stage } \\
\hline 0 & & $11^{9}$ \\
\hline 1 & & 5 \\
\hline 2 & & 7 \\
\hline 3 & & 3 \\
\hline 4 & & 0 \\
\hline Sensorineural symptoms & - & $23 / 26$ \\
\hline \multicolumn{3}{|l|}{ Stage } \\
\hline 0 & & 3 \\
\hline 1 & & 8 \\
\hline 2 & & 7 \\
\hline 3 & & 8 \\
\hline Both WWF and sensorineural symptoms ${ }^{10}$ & - & $20 / 26$ \\
\hline Impaired vibrotactile sense $e^{11}$ & - & $22 / 26$ \\
\hline
\end{tabular}

\section{${ }^{1}$ Median (IQR).}

${ }^{2}$ Patients with HAVS were significantly older than patients with traumatic hand injuries $(p=0.004)$.

${ }^{3}$ Median (range).

${ }^{4}$ Internal drop out: traumatic hand injury $(n=4)$, HAVS $(n=2)$.

CISS score $>50=$ abnormal self-reported cold sensitivity [21].

${ }^{5}$ Disability of the Arm, Shoulder and Hand (DASH). $0=$ no disability

$100=$ most severe disability [24].

${ }^{6}$ Patients with HAVS had significantly higher scores indicating more severe disability $(p=0.001)$.

${ }^{7}$ The 13 -item scale. The scores on each item ranges from 1 (never) to 7 (very often). A high score indicates a strong SOC [18].

${ }^{8} \mathrm{Hand}$ Injury Severity Score [23].

${ }^{9}$ Stockholm Workshop scale [25]. 8 out of 11 patients had cold sensitivity without blanching of skin (i.e. equal to 0.5 in a modified Stockholm Workshop scale, VWF). Staging is based on the highest stage on the most injured hand. ${ }^{10}$ Patients having both a VWF score $\geq 0.5$ and sensorineural score $>0$.

${ }^{11}$ Sensibility index $(\mathrm{SI})<0.8$ in at least one finger [26]. Sl-index is a measure of vibrotactile sense and is a ratio of the integrated area below a test curve and a corresponding age reference population. An index $>0.8$ is regarded as an indication of abnormality [27].

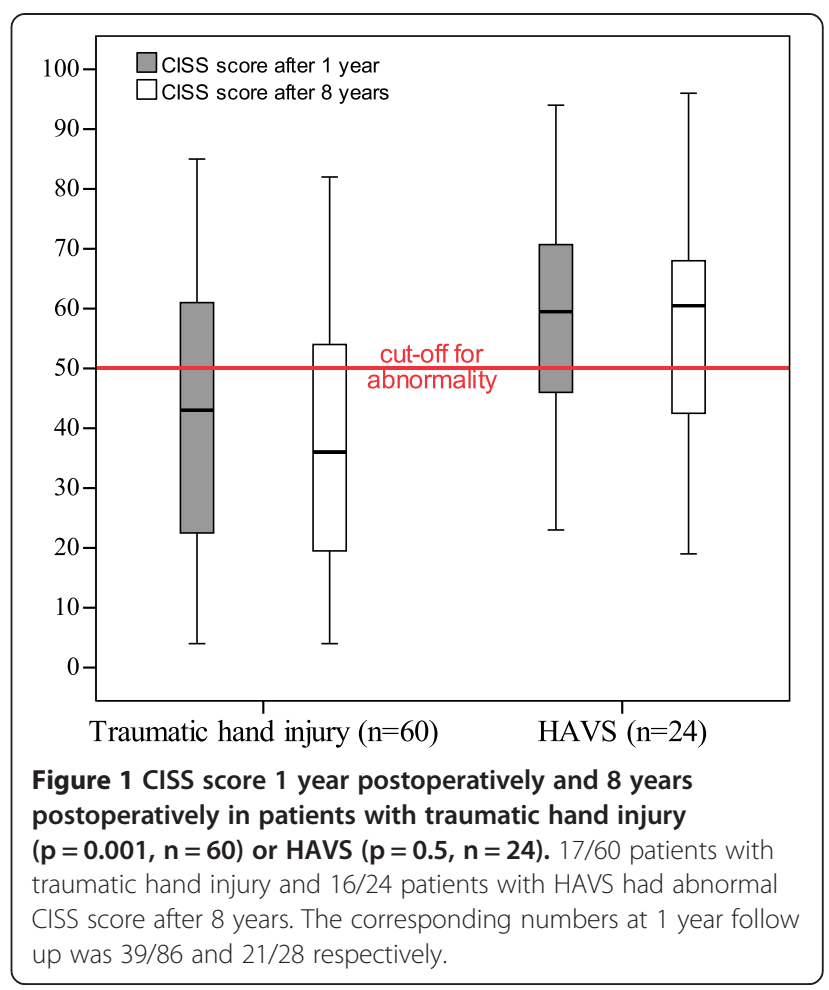

injury had a median HISS score of 77 (10-305) [21]. Fifteen of the 26 patients with HAVS had according to the Stockholm Workshop scale vibration-induced white fingers, 23 of 26 patients had sensorineural symptoms and 20 of 26 had both white fingers and sensorineural symptoms (Table 1). Twenty-two of the 26 patients had an impaired vibrotactile sense. At the present follow-up, fourteen patients with HAVS were retired either due to old age $(n=7)$ or received early retirement pension because of disability or sickness $(n=7)$. Twelve patients worked at the

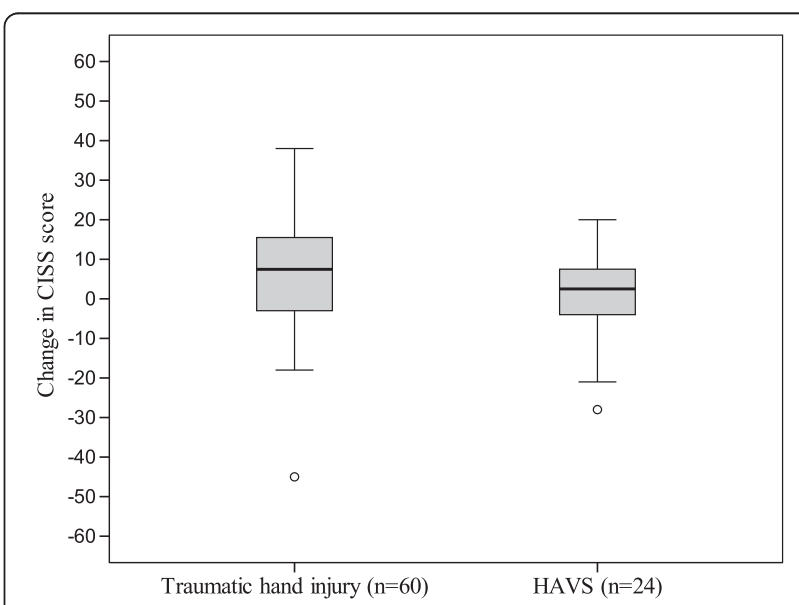

Figure 2 Change in CISS score between 1 year postoperatively and 8 years postoperatively in patients with traumatic hand injury $(n=60, p=0.001)$ or HAVS $(n=24, p=0.50)$. 
Table 2 Responses to the CISS questionnaire at 1 year and 8 years follow-up in patients with traumatic hand injury or HAVS

\begin{tabular}{|c|c|c|c|c|c|c|c|c|c|}
\hline \multirow[t]{2}{*}{ CISS questionnaire $^{1}$} & \multirow[t]{2}{*}{ Score } & \multicolumn{4}{|c|}{ Traumatic hand injury } & \multicolumn{4}{|c|}{ HAVS } \\
\hline & & $\mathrm{n}$ & 1 year $^{2}$ & 8 year $^{2}$ & p-value ${ }^{3}$ & $\mathrm{n}$ & 1 year $^{2}$ & 8 year $^{2}$ & p-value ${ }^{3}$ \\
\hline Total CISS score & $4-100$ & 60 & $45(4-85)$ & $36(4-82)$ & 0.001 & 22 & $60(23-94)$ & $60(19-96)$ & 0.50 \\
\hline 2. How often do you experience these symptoms? & & 60 & $8(2-10)$ & $6(2-10)$ & 0.06 & 22 & $8(2-10)$ & $8(2-10)$ & 1.0 \\
\hline - Continuously/all the time & 10 & & & & & & & & \\
\hline - Several times a day & 8 & & & & & & & & \\
\hline - Once a day & 6 & & & & & & & & \\
\hline - Once a week & 4 & & & & & & & & \\
\hline - Once a month or less & 2 & & & & & & & & \\
\hline $\begin{array}{l}\text { 3. When you develop cold-induced symptoms, on your return } \\
\text { to a warm environment are the symptoms relieved }\end{array}$ & & 60 & $6(2-10)$ & $6(2-10)$ & 0.31 & 22 & $6(2-10)$ & $6(2-10)$ & 1.0 \\
\hline - Within a few minutes & 2 & & & & & & & & \\
\hline - Within 30 minutes & 6 & & & & & & & & \\
\hline - After more than 30 minutes & 10 & & & & & & & & \\
\hline 4. What do you do to ease or prevent your symptoms occurring? & & 62 & $4(0-10)$ & $4(0-10)$ & 0.71 & 22 & $5(0-10)$ & $4(2-10)$ & 0.67 \\
\hline - Take no special action & 0 & & & & & & & & \\
\hline - Keep hand in pocket & 2 & & & & & & & & \\
\hline - Wear gloves in cold weather & 4 & & & & & & & & \\
\hline - Wear gloves all the time & 6 & & & & & & & & \\
\hline - Avoid cold weather/stay indoors & 8 & & & & & & & & \\
\hline - Other & 10 & & & & & & & & \\
\hline \multicolumn{10}{|l|}{$\begin{array}{l}\text { 5. How much does cold bother your injured hand in the } \\
\text { following situations? }\end{array}$} \\
\hline - Holding a glass of ice water & $0-10$ & 62 & $3(0-10)$ & $2(0-10)$ & 0.008 & 22 & $5(0-10)$ & $5(0-10)$ & 0.74 \\
\hline - Holding a frozen package from the freezer & $0-10$ & 60 & $5(0-10)$ & $3(0-10)$ & 0.004 & 22 & $7(0-10)$ & $7(1-10)$ & 0.48 \\
\hline - Washing in cold water & $0-10$ & 62 & $4(0-10)$ & $2(0-10)$ & 0.02 & 22 & $7(0-10)$ & $6(1-10)$ & 0.24 \\
\hline $\begin{array}{l}\text { - When you get out of a hot bath/shower with the air at } \\
\text { room temperature }\end{array}$ & $0-10$ & 62 & $0(0-8)$ & $0(0-8)$ & 0.005 & 22 & $3(0-10)$ & $2(0-10)$ & 0.31 \\
\hline - During cold wintry weather & $0-10$ & 62 & $7(0-10)$ & $5(0-10)$ & 0.06 & 22 & $8(4-10)$ & $8(2-10)$ & 0.18 \\
\hline \multicolumn{10}{|l|}{$\begin{array}{l}\text { 6. Please state how each of the following activities have been } \\
\text { affected as a consequence of cold-induced symptoms in your } \\
\text { injured hand and score each. }\end{array}$} \\
\hline - Domestic chores & $0-4$ & 62 & $1(0-4)$ & $0(0-4)$ & 0.044 & 22 & $2(0-3)$ & $2(0-4)$ & 0.72 \\
\hline - Hobbies and interests & $0-4$ & 62 & $2(0-4)$ & $1(0-4)$ & 0.16 & 24 & $3(0-4)$ & $2(0-4)$ & 0.63 \\
\hline - Dressing and undressing & $0-4$ & 62 & $0(0-4)$ & $1(0-4)$ & 0.17 & 22 & $1(0-4)$ & $1(0-4)$ & 0.79 \\
\hline - Tying your shoe laces & $0-4$ & 62 & $1(0-4)$ & $1(0-4)$ & 0.06 & 22 & $2(0-4)$ & $1(0-4)$ & 0.22 \\
\hline - Your job & $0-4$ & 62 & $2(0-4)$ & $2(0-4)$ & 0.04 & 22 & $3(0-4)$ & $2(0-4)$ & 0.37 \\
\hline
\end{tabular}

${ }^{1}$ Question no 1 is not included in the total CISS score. See Table 3 for details. ${ }^{2}$ Median values (range).

${ }^{3}$ Wilcoxon's signed rank test. Bold $=$ statistical significance.

time for the investigation, but nine of these patients had changed work or work tasks during the 8-year follow up to eliminate vibration exposure. The remaining three patients with HAVS had an average of 2 hours/day of vibration exposure with tools, such as grinding machines and power drills. All patients avoided vibration exposure during leisure with the exception of minor exposure when e.g. cutting the lawn or using an electric drill.

\section{Change in self-reported cold sensitivity (CISS score) between 1 and 8 year follow up}

There was a significant change in the total CISS score for patients with traumatic hand injury $(\mathrm{p}=0.001, \mathrm{n}=60)$, indicating less problems with cold sensitivity over time, in contrast to those with HAVS $(\mathrm{p}=0.50, \mathrm{n}=24)$, (Figures 1 and 2, Table 2). Patients with traumatic hand injuries experienced significantly less problems over time with 
Table 3 Perceived symptoms on cold exposure at 1 and 8 years follow-up in patients with traumatic hand injury or HAVS

\begin{tabular}{|c|c|c|c|c|c|c|c|c|c|}
\hline \multirow[t]{2}{*}{ Perceived symptoms on cold exposure ${ }^{1}$} & \multirow[t]{2}{*}{ Score } & \multicolumn{4}{|c|}{ Traumatic hand injury } & \multicolumn{4}{|c|}{ HAVS } \\
\hline & & $\bar{n}$ & 1 year $^{2}$ & 8 years $^{2}$ & p-value ${ }^{3}$ & $\bar{n}$ & 1 year $^{2}$ & 8 years $^{2}$ & p-value ${ }^{3}$ \\
\hline Pain & $0-10$ & 54 & $3(0-6)$ & $3(0-5)$ & 0.46 & 18 & $6(3-8)$ & $6(2-7)$ & 0.25 \\
\hline Numbness & $0-10$ & 51 & $4(1-6)$ & $3(0-6)$ & 0.07 & 18 & $6(4-8)$ & $7(5-8)$ & 0.87 \\
\hline Stiffness & $0-10$ & 53 & $5(2-7)$ & $4(1-6)$ & 0.001 & 22 & $7(4-8)$ & $6(4-8)$ & 0.53 \\
\hline Weakness & $0-10$ & 52 & $5(1-7)$ & $3(1-6)$ & 0.004 & 19 & $7(4-8)$ & $5(4-7)$ & 0.04 \\
\hline Aching & $0-10$ & 57 & $3(0-7)$ & $2(0-5)$ & 0.12 & 19 & $6(4-8)$ & $7(4-8)$ & 0.85 \\
\hline Swelling & $0-10$ & 58 & $0(0-2)$ & $0(0-1)$ & 0.18 & 21 & $0(0-4)$ & $2(0-5)$ & 0.11 \\
\hline Skin colour change & $0-10$ & 53 & $3(0-7)$ & $2(0-5)$ & 0.001 & 17 & $6(4-8)$ & $5(3-8)$ & 0.14 \\
\hline
\end{tabular}

"Question no 1 in the CISS questionnaire: "Which of the following symptoms of cold intolerance do you experience in your injured limb on exposure to cold?" $(0=$ no symptoms/trouble at all and $10=$ the most severe symptoms/trouble you can possibly imagine).

${ }^{2}$ Median values $\left(q_{1}-q_{3}\right)$.

${ }^{3}$ Wilcoxon's signed rank test. Bold $=$ statistical significance.

stiffness, weakness and skin colour change on cold exposure, but not with pain, aching, numbness and swelling (Table 3). The only symptom that patients with HAVS experienced significantly less problems with was weakness on cold exposure (Table 3).

Patients with traumatic hand injuries also experienced less problems when exposed to cold during daily activities, e.g. when holding a glass of ice water or frozen package, when being exposed to cold water or temperature shifts, such as getting out of a hot bath/shower with the air at room temperature. The negative impact of cold-induced symptoms during domestic chores and at work was also improved. There was no significant change in the time needed to experience relief of symptoms on return to a warm environment, nor was any improvement noted when engaged in hobbies or interests or when being exposed to cold wintry weather. For patients with HAVS no significant change in cold sensitivity was noted for any of the situations included in the CISS questionnaire (Table 2).

\section{Predictors for change over time in self-reported cold sensitivity for traumatic hand injuries}

None of the factors listed in Tables 4 and 5 were significantly associated with change in cold sensitivity at 8-year follow up. The presence of bone injury, a larger number of repaired vessels, the use of vascular grafts and a high Hand Injury Severity Score (HISS) were linked to worse CISS scores at one year follow up [21], but failed to show any significant association for change in self reported cold sensitivity in the present long term follow up.

\section{Self reported cold sensitivity and sense of coherence}

A lower sense of coherence score correlated significantly with worse cold sensitivity (CISS score) in both patient groups at the 8-year follow up (trauma group: $\mathrm{r}^{\mathrm{s}}=0.31$, p-value 0.016, HAVS group: $\mathrm{r}^{\mathrm{s}}=0.47$, $\mathrm{p}$-value 0.027). However, there was no significant relationship ( $\mathrm{p}$-value = 0.26 ) between the sense of coherence score and change in cold sensitivity between the 1 and 8 year follow up. In addition, there was no significant difference in the sense of coherence score between patients with traumatic hand injury or HAVS $(\mathrm{p}=0.21)$.

\section{Discussion}

Our results showed a significant long-term improvement (total CISS score) in self-reported cold sensitivity in patients with traumatic hand-injury. However, there was no improvement in pain levels on cold exposure or time needed to feel relief of symptoms on return to a warm environment, nor was any improvement noted when engaged in leisure activities or when being exposed to cold wintry weather. None of the predictors were significantly linked to any change in cold sensitivity in patients with traumatic hand-injury. For patients with HAVS no significant change was noted in total CISS score or in any of the included questions in the CISS questionnaire. A lower sense of coherence score correlated significantly with worse cold sensitivity (total CISS score) in both patient groups at 8-year follow up.

\section{Table 4 Predictors (quantitative variables) of change in self-reported cold sensitivity (CISS score 4-100) among patients with traumatic hand injuries}

\begin{tabular}{lll}
\hline Continuous variables & \multicolumn{2}{l}{ Change in CISS score (4-100) $(\mathbf{n}=\mathbf{5 9 - 6 0 )}$} \\
\cline { 2 - 3 } & $\mathbf{r}_{\mathbf{s}}{ }^{\mathbf{1}}$ & $\mathbf{p}$-value \\
\hline Age & 0.17 & 0.18 \\
Time after injury (months) & -0.10 & 0.44 \\
HISS score ${ }^{2}$ & 0.12 & 0.38 \\
Number of repaired nerves & -0.02 & 0.90 \\
Number of injured vessels & 0.04 & 0.75 \\
Number of repaired vessels & 0.02 & 0.88 \\
Number of surgical sessions & 0.04 & 0.79 \\
\hline
\end{tabular}

${ }^{1}$ Spearman rank correlation test.

${ }^{2}$ Hand Injury Severity Score, higher score indicates worse anatomical damage. 
Table 5 Predictors (categorical variables) of change in self-reported cold sensitivity (CISS; score range 4-100) among patients with traumatic hand injuries

\begin{tabular}{|c|c|c|c|c|}
\hline \multirow{2}{*}{\multicolumn{2}{|c|}{ Multiple and dichotomous predictors }} & \multicolumn{3}{|c|}{ Change in total CISS score (4-100) } \\
\hline & & \multirow{2}{*}{$\begin{array}{l}\mathbf{n} \\
46\end{array}$} & \multirow{2}{*}{$\begin{array}{l}\text { Md (q1, q3) } \\
5(-3,16)\end{array}$} & \multirow{2}{*}{$\begin{array}{l}\text { p-value } \\
0.75\end{array}$} \\
\hline Gender & Male & & & \\
\hline & Female & 14 & $10(-5,14)$ & \\
\hline \multirow[t]{2}{*}{ Smoking } & No & 46 & $10(-3,17)$ & 0.23 \\
\hline & Yes & 14 & $2(-4,12)$ & \\
\hline \multirow[t]{3}{*}{ Injured side } & Dominant & 27 & $3(-3,13)$ & 0.37 \\
\hline & Non dominant & 31 & $9(-3,18)$ & \\
\hline & Bilateral & 2 & $-15(-45)$ & \\
\hline \multirow[t]{2}{*}{ Injured digit(s) } & Single digit & 17 & $6(-5,14)$ & 0.918 \\
\hline & Multiple digits & 17 & $9(-3,17)$ & \\
\hline \multirow[t]{4}{*}{ Level of injury } & Distal to the MCP joint level & 30 & $9(-3,16)$ & 0.77 \\
\hline & Mid palm and dorsal hand & 19 & $1(-6,17)$ & \\
\hline & Proximal hand & 4 & $5(-3,22)$ & \\
\hline & Wrist and forearm & 7 & $9(1,14)$ & \\
\hline \multirow[t]{3}{*}{ Type of injury } & Sharp & 32 & $3(-3,16)$ & 0.63 \\
\hline & Laceration & 20 & $10(3,15)$ & \\
\hline & Crush & 8 & $7(-11,29)$ & \\
\hline \multirow[t]{2}{*}{ Soft tissue damage } & No & 33 & $3(-6,14)$ & 0.06 \\
\hline & Yes & 27 & $10(2,17)$ & \\
\hline \multirow[t]{4}{*}{ Soft tissue repair } & None & 8 & $8(-15,17)$ & 0.37 \\
\hline & Skin suture & 38 & $2(-3,15)$ & \\
\hline & Split skin & 12 & $12(7,16)$ & \\
\hline & Flap & 2 & $13(2)$ & \\
\hline \multirow[t]{2}{*}{ Bone injury } & No & 30 & $2(-5,16)$ & 0.19 \\
\hline & Yes & 30 & $10(-2,16)$ & \\
\hline \multirow[t]{3}{*}{ Osteosynthetic material } & None & 37 & $2(-3,17)$ & 0.53 \\
\hline & Pins/Wire & 13 & $10(5,16)$ & \\
\hline & Screws or plate & 10 & $12(-6,16)$ & \\
\hline \multirow[t]{2}{*}{ Removal of osteo-synthetic material } & No & 2 & $25(11)$ & 0.19 \\
\hline & Yes & 14 & $12(9,14)$ & \\
\hline \multirow[t]{2}{*}{ Tendon injury } & No & 20 & $3(-2,17)$ & 0.97 \\
\hline & Yes & 40 & $9(-3,15)$ & \\
\hline \multirow[t]{2}{*}{ Vascular grafts } & No & 49 & $3(-3,15)$ & 0.16 \\
\hline & Yes & 10 & $13(7,17)$ & \\
\hline \multirow[t]{7}{*}{ Nerve injury } & No nerve injury & 5 & $3(-5,18)$ & 0.39 \\
\hline & Median nerve & 10 & $-5(-6,13)$ & \\
\hline & Ulnar nerve & 5 & $17(9,20)$ & \\
\hline & Median and ulnar or multiple nerves & 3 & $-1(-45)$ & \\
\hline & Radial nerve & 5 & $9(-11,12)$ & \\
\hline & One digital nerve & 5 & $14(-2,20)$ & \\
\hline & Two or multiple digital nerves or common digital nerve & 26 & $10(-3,15)$ & \\
\hline
\end{tabular}




\begin{tabular}{|c|c|c|c|c|}
\hline \multirow[t]{3}{*}{ Nerve injury } & Complete & 46 & $8(-3,15)$ & 0.26 \\
\hline & Partial & 5 & $-3(-6,11)$ & \\
\hline & Contusion & 6 & $20(14,31)$ & \\
\hline \multirow[t]{2}{*}{ Repaired nerve } & No & 36 & $8(-3,15)$ & 0.83 \\
\hline & Yes & 14 & $3(-3,14)$ & \\
\hline \multirow[t]{2}{*}{ Revascularisation } & No & 51 & $4(-3,15)$ & 0.60 \\
\hline & Yes & 9 & $12(-6,19)$ & \\
\hline \multirow[t]{2}{*}{ Replantation } & No & 48 & $4(-3,17)$ & 0.88 \\
\hline & Yes & 12 & $10(-3,13)$ & \\
\hline \multirow[t]{3}{*}{ Post operative pain relief } & None & 4 & $6(-13,10)$ & 0.87 \\
\hline & Oral & 25 & $9(-3,17)$ & \\
\hline & Injection & 23 & $6(2)$ & \\
\hline
\end{tabular}

*Mann-Whitney U-Test was used for dichotomous variables and Kruskal-Wallis was used for variables with multiple categories.

There are few long-term studies on the prolonged effect of cold sensitivity and among them the results are contradictory. Furthermore, the use of different outcome measures, such as single yes or no questions, verbal or numeric rating scales or more extensive questionnaires, make comparisons difficult. Many studies on nerve injuries indicate that there is no significant change in cold sensitivity over time for the majority of patients $[8,11]$. For amputation injuries, with or without replantation, some studies report weakened problems with time, while others report very little improvement [28-30]. Nancarrow et al. reported unchanged problems at 5-year follow up for a mixed population of traumatic hand injuries, which is in line with the results of Gustafsson et al. at a 10-year follow up. Riaz et at concluded that around half of a patient group with flexor tendon injuries had persistent problems after 10.6 years $[7,13,31]$. In a prospective cohort study of all patients with acute trauma to the hand or forearm, Craigen et al. found that the degree of cold sensitivity increased rapidly up to three months, then plateaued and remained unchanged for at least eight months. A reduction in discomfort over a period of three years was most pronounced in patients with severe symptoms [12]. This finding is in contrast with Povlsen et al., who did not find any improvement in severely affected patients 12 years after digital replantation, but some improvement in patients with initial moderate discomfort [15]. Our findings support an improvement in cold sensitivity for patients with traumatic hand injuries as measured by the total CISS score. Thus, important information about e.g. pain levels (CISS question no 1) on cold exposure, which is not included in the total score, did not change significantly over time, nor did the time needed for relief of symptoms on return to a warm environment or discomfort when engaged in leisure activities or during cold wintry weather (CISS question no 3, 5 and 6) Although the CISS questionnaire, with its total score, is considered reliable and the content and construct validity has been good [22], our findings highlight the importance to view each individual question since the included questions in CISS is not weighted and important information otherwise will be lost.

In our previous study, we found that a high HISS score indicating more severely injured hands correlated with abnormal cold sensitivity (CISS score $>50$ ), but not with any change in CISS score at the present 8-year follow up [21]. Thus, the severity of the hand injury did not predict change in cold sensitivity over time. We have no explanation for the lack of predictors, but one may speculate that there is maturation over time in such injuries and possibly also a component of coping. A limitation of the study may also be that there are a limited number of patients. There may be a risk that we do not see any effect of certain variables.

Surprisingly, there were a few patients with HAVS that were still exposed to vibrations. The general recommendation for this patient group with problems of e.g. cold sensitivity is that vibration exposure should be avoided. Furthermore, our long-term follow up of patients suffering from HAVS clearly showed that they experienced unchanged problems on cold exposure, which is interesting in view of the pathophysiology with a neural component as the cause of the symptoms. In contrast, patients with diabetes and a carpal tunnel syndrome experience remaining symptoms with cold sensitivity after carpal tunnel release at one year, but not at five years after the release $[32,33]$. Thus, different types of neuropathies may have diversity in their development and or their adaptation to cold sensitivity, or both.

Thus, the improvement after 8 years seen in our patients with a traumatic hand injury may be a result of an actual improvement or a result of an adaptation process. Such an 
adaptation process has been previously described and the importance of access to relieving strategies for hand injured patients has been highlighted [17]. These strategies could e.g. be use of heating remedies, proper gloves, overall warm general clothing and a choice of tools with a surface layer causing less cold exposure. To put injured hand in armpit, to exercise or actively move the affected hand, to change grip pattern or hide the injured hand when opening the refrigerator, to increase indoor temperature, turning off ventilation/air conditioning or avoiding cold water may be other alternatives. At 1 year follow up abnormal cold sensitivity (CISS score > 50) was seen in $45 \%$ and $75 \%$ of patients with traumatic hand injury and HAVS respectively [1]. The corresponding percentage of abnormality was for those responded at the present 8-year follow up, $28 \%$ and $62 \%$ respectively. The majority of the included questions in the total CISS score focus on the impact of cold sensitivity on activities in daily life. Our result mirrors an increased ability for patients with traumatic hand injury to master challenges in daily life caused by cold exposure. Adaptation strategies as described above probably played an important role in that process. Especially, since symptoms, such as pain, aching and numbness, did not improve significantly; neither did the time needed to experience relief on return to a warm environment in our patient groups.

A novel finding in this study was the significant relationship between worse self-reported cold sensitivity (CISS score) and a lower sense of coherence in both patient groups. For more than 20 years ago the American-Israeli medical sociologist Aaron Antonovsky introduced his salutogenic theory 'sense of coherence' as a global orientation to view the world, claiming that the way people view their life has a positive influence on their health. Sense of coherence explains why people in stressful situations stay well and even are able to improve their health. The person's ability or disposition to see the world as comprehensible, manageable and meaningful is therefore reflected in the SOC questionnaire $[18,34]$. How patients with a severe hand injury adapt to the consequences of cold sensitivity in daily life may very well be linked to an ability to view a new situation in life according to these perspectives. This seems to be especially important when severe cold sensitivity result in changed life roles e.g. a work role or the role of being a parent. The alterations in or loss of work tasks or the ability to take part in leisure activities with spouse and children has previously been described to cause frustration and distress and even influence self-image [17].

\section{Conclusion}

We conclude that the negative impact of cold sensitivity on activities in daily life improved during the 8-year follow up for patients with traumatic hand injury despite unchanged problems with symptoms, such as pain/aching and numbness on cold exposure, and that the time needed to experience relief on return to a warm environment did not improve. In contrast, patients with HAVS did not show any significant improvement. Interestingly, a low SOC was associated with worse cold sensitivity (CISS score) in such groups of patients. Information should be provided about relieving strategies to assist patient's adaptation process.

\section{Competing interests}

The authors declare that they have no competing interests.

\section{Authors' contributions}

IC designed the study and performed the statistical analysis. IC and LD interpreted the findings and drafted the manuscript. Both authors read and approved the final manuscript.

\section{Acknowledgements}

The study was supported by grants from the Swedish Research Council (Medicine), Skåne University Hospital, Lund University and Region Skåne (i.e. ALF grants).

Received: 16 May 2013 Accepted: 28 February 2014 Published: 14 March 2014

\section{References}

1. Carlsson IK, Rosen B, Dahlin LB: Self-reported cold sensitivity in normal subjects and in patients with traumatic hand injuries or hand-arm vibration syndrome. BMC Musculoskelet Disord 2010, 11:89.

2. Kay S: Venous occlusion plethysmography in patients with cold related symptoms after digital salvage procedures. J Hand Surg [Br] 1985, 10(2):151-154.

3. Klocker J, Peter T, Pellegrini L, Mattesich M, Loescher W, Sieb M, Klein-Weigel P, Fraedrich G: Incidence and predisposing factors of cold intolerance after arterial repair in upper extremity injuries. J Vasc Surg 2012, 56(2):410-414

4. McKirdy SW, Jacobs N, Nassab R, Starley IF: A retrospective review of cold intolerance following corrective surgery for Dupuytren's disease. $\mathrm{Br} \mathrm{J}$ Hand Ther 2007, 12(2):55-59.

5. Nijhuis TH, Smits ES, Jaquet JB, Van Oosterom FJ, Selles RW, Hovius SE: Prevalence and severity of cold intolerance in patients after hand fracture. J Hand Surg Eur 2009, 35(4):306-11.

6. Novak $C$, Anastakis D, Beaton D, Mackinnon S, Katz J: Cold intolerance after brachial plexus nerve injury. Hand 2012, 7(1):66-71.

7. Riaz M, Hill C, Khan K, Small JO: Long term outcome of early active mobilization following flexor tendon repair in zone 2. J Hand Surg [Br] 1999, 24(2):157-160.

8. Ruijs AC, Jaquet JB, Van Riel WG, Daanen HA, Hovius SE: Cold intolerance following median and ulnar nerve injuries: prognosis and predictors. J Hand Surg Eur Vol 2007, 32(4):434-439.

9. Stromberg T, Dahlin LB, Lundborg G: Hand problems in 100 vibration-exposed symptomatic male workers. J Hand Surg [Br] 1996, 21(3):315-319.

10. Tark KC, Kim YW, Lee YH, Lew JD: Replantation and revascularization of hands: clinical analysis and functional results of 261 cases. $J$ Hand Surg [Am] 1989, 14(1):17-27.

11. Collins ED, Novak CB, Mackinnon SE, Weisenborn SA: Long-term follow-up evaluation of cold sensitivity following nerve injury. J Hand Surg [Am] 1996, 21(6):1078-1085.

12. Craigen M, Kleinert JM, Crain GM, McCabe SJ: Patient and injury characteristics in the development of cold sensitivity of the hand: a prospective cohort study. J Hand Surg [Am] 1999, 24(1):8-15.

13. Gustafsson M, Hagberg L, Holmefur M: Ten years follow-up of health and disability in people with acute traumatic hand injury: pain and cold sensitivity are long-standing problems. J Hand Surg Eur Vol 2011, 36(7):590-598

14. Irwin MS, Gilbert SE, Terenghi G, Smith RW, Green CJ: Cold intolerance following peripheral nerve injury. Natural history and factors predicting severity of symptoms. J. Hand Surg [Br] 1997, 22(3):308-316. 
15. Povlsen B, Nylander G, Nylander E: Cold-induced vasospasm after digital replantation does not improve with time. A 12-year prospective study. $J$ Hand Surg $[B r] 1995,20(2): 237-239$.

16. Cederlund R, Thoren-Jonsson AL, Dahlin LB: Coping strategies in daily occupations 3 months after a severe or major hand injury. Occup Ther Int 2010, 17(1):1-9.

17. Carlsson IK, Edberg AK, Wann-Hansson C: Hand-injured patients' experiences of cold sensitivity and the consequences and adaptation for daily life: a qualitative study. J Hand Ther 2010, 23(1):53-61. quiz 2.

18. Eriksson M, Lindstrom B: Validity of Antonovsky's sense of coherence scale: a systematic review. J Epidemiol Community Health 2005, 59(6):460-466.

19. Cederlund Rl, Ramel E, Rosberg HE, Dahlin LB: Outcome and clinical changes in patients 3, 6, 12 months after a severe or major hand injury-can sense of coherence be an indicator for rehabilitation focus? BMC Musculoskelet Disord 2010, 11:286.

20. Antonovski A: Unraveling the Mysteries of Health. San Francisco: Josey Bass: Josey Bass; 1987.

21. Carlsson IK, Nilsson JA, Dahlin LB: Cut-off value for self-reported abnormal cold sensitivity and predictors for abnormality and severity in hand injuries. J Hand Surg Eur Vol 2010, 35(5):409-416.

22. Carlsson I, Cederlund R, Hoglund P, Lundborg G, Rosen B: Hand injuries and cold sensitivity: reliability and validity of cold sensitivity questionnaires. Disabil Rehabil 2008, 30(25):1920-1928.

23. Campbell DA, Kay SP: The Hand Injury Severity Scoring System. $J$ Hand Surg [Br] 1996, 21(3):295-298.

24. Atroshi I, Gummesson C, Andersson B, Dahlgren E, Johansson A: The disabilities of the arm, shoulder and hand (DASH) outcome questionnaire: reliability and validity of the Swedish version evaluated in 176 patients. Acta Orthop Scand 2000, 71(6):613-618.

25. Brammer AJ, Taylor W, Lundborg G: Sensorineural stages of the hand-arm vibration syndrome. Scand J Work Environ Health 1987, 13(4):279-283.

26. Lundborg G, Dahlin LB, Lundstrom R, Necking LE, Stromberg T: Vibrotactile function of the hand in compression and vibration-induced neuropathy. Sensibility index-a new measure. Scand I Plast Reconstr Surg Hand Surg 1992, 26(3):275-279.

27. Stromberg T, Dahlin LB, Lundborg G: Vibrotactile sense in the hand-arm vibration syndrome. Scand J Work Environ Health 1998, 24(6):495-502.

28. Gelberman RH, Urbaniak JR, Bright DS, Levin LS: Digital sensibility following replantation. J Hand Surg [Am] 1978, 3(4):313-319.

29. Paavilainen P, Nietosvaara Y, Tikkinen KA, Salmi T, Paakkala T, Vilkki S: Long-term results of transmetacarpal replantation. J Plast Reconstr Aesthet Surg 2007, 60(7):704-709.

30. Urbaniak JR, Roth JH, Nunley JA, Goldner RD, Koman LA: The results of replantation after amputation of a single finger. $J$ Bone Joint Surg Am 1985, 67(4):611-619.

31. Nancarrow JD, Rai SA, Sterne GD, Thomas AK: The natural history of cold intolerance of the hand. Injury 1996, 27(9):607-611.

32. Thomsen NO, Cederlund R, Rosen I, Bjork J, Dahlin LB: Clinical outcomes of surgical release among diabetic patients with carpal tunnel syndrome: prospective follow-up with matched controls. J Hand Surg Am 2009, 34(7):1177-1187.

33. Thomsen NO, Cederlund RI, Andersson GS, Rosén I, Björk J, Dahlin LB: Carpal tunnel release in patients with diabetes: a 5-year follow-up with matched controls. J Hand Surg Am 2014. doi:10.1016/j.jhsa.2014.01.012. [Epub ahead of print].

34. Lindstrom B, Eriksson M: Salutogenesis. J Epidemiol Community Health 2005, 59(6):440-442.

doi:10.1186/1471-2474-15-83

Cite this article as: Carlsson and Dahlin: Self-reported cold sensitivity in patients with traumatic hand injuries or hand-arm vibration syndrome an eight year follow up. BMC Musculoskeletal Disorders 2014 15:83.

\section{Submit your next manuscript to BioMed Central and take full advantage of:}

- Convenient online submission

- Thorough peer review

- No space constraints or color figure charges

- Immediate publication on acceptance

- Inclusion in PubMed, CAS, Scopus and Google Scholar

- Research which is freely available for redistribution

Submit your manuscript at www.biomedcentral.com/submit
Ciomed Central 